\title{
Reseña de la obra de teatro \\ Conejo Blanco-Conejo Rojo: Innovación teatral \\ y aportación en la industria del entretenimiento
}

Brenda Rodríguez Peña ${ }^{1}$

https://doi.org/10.36105/stx.2018n1.14

Conejo Blanco-Conejo Rojo ( $C B-C R$ ) es una obra de teatro escrita por Nassim Soleimanpour que surge de la historia del propio autor cuando, al no querer hacer su servicio militar por negarse a interrumpir su carrera teatral, le prohíben salir de su país, Irán, negándole el pasaporte. En consecuencia, ideó una trama ingeniosa para viajar y hacer oír su voz a través del mundo, aunque fuera sin su presencia, con lo que logró colocar su obra en varias partes del mundo, en 15 idiomas distintos. $C B-C R$ se estrenó en 2011 en el Festival de Canadá Summerworks, sin que él pudiera presenciarla (Youngs, 2016).

Cada noche, durante la temporada de esta puesta en escena, aparece sobre el escenario solamente un actor que brinda la función, siendo esa la única vez que la podrá representar. Lo innovador de la obra es que el actor/actriz no conoce el tema ni el guion sino hasta 48 horas antes del día de su presentación. Poco antes, recibe un correo electrónico en el cual se le dan algunas instrucciones breves para su preparación; la noche de su debut encuentra un sobre cerrado en una mesa del escenario, en ese instante lo abre y es entonces cuando tiene su primer acercamiento al guion, se entera del tema y de la dinámica de su presentación (Fierro, 2016).

Lo anterior resulta un gran desafío para el actor/actriz que tratará de interpretar lo que Soleimanpour desea transmitir, sin dirección ni ensayos, únicamente con la guía del texto.

1 Licenciada en Periodismo y Comunicación Colectiva por la Universidad Nacional Autónoma de México (UNAM). Diplomados en Diseño Editorial (UNAM) y en Periodismo Digital (ITESM). Estudia la Maestría en Dirección de Empresas de Entretenimiento y es auxiliar de investigación en el Centro de Investigación para la Comunicación Aplicada (CICA) de la Facultad de Comunicación de la Universidad Anáhuac México. 
La misma trama, la misma obra de teatro para todos los actores invitados a tomar el reto, y ocurre solamente una vez en su vida.

También es un reto para el público no poder compartir personalmente ni por ningún medio de qué trata la obra, por petición del mismo autor y por ser una necesidad intrínseca a la obra. ¿Cómo ir a presenciar un espectáculo y estar obligado a no revelar la historia?

La puesta en escena ha creado expectativa por su innovación y misterio, también porque el elenco no está compuesto necesariamente de actores o actrices; entre los que han representado la obra se encuentran, por ejemplo, cantantes que no tienen experiencia en la actuación.

Se trata de una forma innovadora de cambiar la manera de presentar la creación de contenidos, dándole un giro de misterio y, a la vez, una aportación para la industria del entretenimiento en cuanto a la forma de vivir la experiencia. Al público le llama la atención asistir a este tipo de producciones debido a que puede ir a ver varias funciones de la misma obra, y en cada una de ellas se encontrará una obra y una experiencia diferente, debido a que cada actor la resolverá a su modo y según su percepción; por lo tanto, puede que resulte una obra totalmente distinta.

En este mundo revolucionario y de constante movimiento, se requieren más productores que aporten contenidos nuevos, que innoven la manera en que se vive el teatro, cambiando las formas acostumbradas y tradicionales por nuevas experiencias en el ámbito del entretenimiento.

\section{Referencias}

Fierro, G. (4 de julio de 2016). Una obra que no requiere dirección, ni ensayo, sólo un actor que desconozca el guion: Conejo Blanco, Conejo Rojo. Recuperado de Cartelera de Teatro: http://carteleradeteatro.mx/2016/conejo-blanco-conejo-rojo-una-obra-de-teatro-que-no-requiere-direccion-niensayo-solo-un-actor-que-desconozca-el-guion.

Youngs, I. (4 de julio de 2016). Playwright Nassim Soleimanpour sees bis own play. Recuperado de BBC: http://www.bbc.com/news/entertainment-arts-21577030. 